\title{
E-Commerce Business Model Innovation Under the Background of Internet Celebrity Economy
}

\author{
Jiawei Pang ${ }^{1, *}$
}

\author{
${ }^{1}$ RDFZ Chaoyang Branch School, Beijing 100028, China \\ *Jiawei Pang. Email: wangqixin3@126.com
}

\begin{abstract}
The Internet celebrity economy was born in 2016. It refers to the image of young and beautiful fashionistas, and the vision and taste of celebrities to promote and promote. Internet celebrities will accumulate a large number of fans on social media, and then rely on the power of a huge fan base to promote their products. Fans are the main purchasing power of their products. The current vigorous development of the Internet celebrity economy is inseparable from the convenience of e-commerce. Fans have brought huge profits to Internet celebrities in e-commerce, and the phenomenon of Internet celebrities has turned into an economic phenomenon, especially during the epidemic. As a new type of business model, e-commerce applies the 4R theory to bring continuous customer value for enterprises, and conforms to the development trend of e-commerce based on social interaction. Based on this premise, small and medium-sized enterprises can also adapt to marketing methods such as the Internet celebrity economy.
\end{abstract}

Keywords: Internet celebrity economy, e-commerce, business model

\section{INTRODUCTION}

\subsection{Research Background}

Since the 21 st century, e-commerce has spread all over the world from its infancy to now. In the beginning, the e-commerce platform was mainly Taobao, but now there are countless various online shopping platforms, and live broadcast marketing methods have emerged. In early 2020, the sudden outbreak and rapid spread of the epidemic had to force people to stay at home. The closure of offline physical stores and shopping malls has brought opportunities for the development of the "economy" on the Internet. Since January, major live broadcasts, short video platforms such as Douyin, and social media, such as Weibo, have more and more live broadcasts with goods, and the anchors with goods are no longer limited to Internet celebrities and entertainment circles. Artists have also begun to carry out sales and other marketing. As more and more companies set foot in the field of Internet celebrity economy, small and medium-sized ecommerce are also trying to profit from fan groups. However, in the face of fierce competition, small and medium-sized e-commerce faces many challenges.

\subsection{Research Significance}

This article mainly focuses on the research of the business model of small and medium-sized e-commerce in the context of the Internet celebrity economy. With the torrent of Internet celebrity economy and high-intensity competition, the survival of small and medium-sized ecommerce companies is particularly difficult. This article analyzes the theory of the Internet celebrity economy, the pros and cons, and the relevant theories of the ecommerce market, and provides reasonable and innovative methods for the characteristics and pros and cons of small and medium-sized enterprises, and is committed to helping small and medium-sized ecommerce companies survive and profit in the market.

\section{LITERATURE REVIEW}

\subsection{Research on the Internet Celebrity Economy}

Internet celebrities are the most socially concerned concept in 2016, and many scholars have defined their concept. Yang Chunyao (2017) believes that in terms of the concept of Internet celebrities, "net" refers to the Internet, and "red" refers to something that has received constant attention from the public. The essence of cyber celebrities is to obtain attention through the Internet. 
Powerful people [1]. Wang Jing (2016) believes that Internet celebrities currently refer to celebrities who interact with netizens through the Internet media to attract and focus the attention of a large number of fans, and that "the emergence of cyber celebrities is not spontaneous, but the Internet celebrities, Internet promoters, traditional media, and the psychological needs of audiences. [2]. Zhou Ping (2017) defines Internet celebrities as "people who become popular through the Internet", referring to personal appearances, behaviors or events. The people who have attracted widespread attention on the network platform mainly refer to the celebrities who gather a large number of fans through the network and realize commercial realization. It can be seen that the network celebrities are the products of the development of the "decentralized" network information dissemination model in the mobile Internet era to a certain stage. We are more inclined to the interpretation given by Baidu Baike, that is, Internet celebrities refer to people who become popular by netizens because of certain events, behaviors or continuous output of certain content in reality or online life. Popularity is due to the fact that some of its own characteristics are amplified under the influence of the Internet, and are in line with the psychology of netizens such as aesthetics, ugliness, entertainment, stimulation, voyeurism, imagination, taste, and spectators, and are sought after by the Internet world intentionally or unintentionally. Become an "Internet celebrity" [3].

Related research on e-commerce of Internet celebrities has also been a hot spot in my country's ecommerce field since 2016. Ding Zhongxian and $\mathrm{Xu}$ Wanting (2016) believe that Internet celebrity ecommerce is the "Internet celebrity" + "e-commerce" model, which refers to the beauties, opinion leaders and industry experts who have certain social assets on social media and recommend them through social platforms. A business model that is finally realized through ecommerce [4]. Liu Xiaoqian, Yu Yangfei and Han Mei (2017) believe that Internet celebrity e-commerce is an industrial chain centered on cyber celebrities. In this industry chain, cyber celebrities are the "opinion leaders" of products and are in the e-commerce leader. The stream layer aims to convert the fan traffic carried by itself into fan purchasing power through product recommendation and multi-platform promotion [5]. Du Lishuang (2017) divides the development of Internet celebrity ecommerce into three stages according to time, namely, the budding period, the development period and the prosperity period. Xu Danfen (2016) believes that with the emergence of online celebrity incubation platforms such as live broadcasts, the types of e-commerce celebrities will also show a growing trend [6].

\subsection{Research on Small and Medium E- commerce and Its Business Model}

In the development wave of the Internet economy, several major e-commerce giants and emerging Internet celebrity's e-commerce have a huge market share. On the contrary, the business model and development status of small and medium-sized enterprises is a corner that has not been taken seriously until the "Double Eleven" war that has become more and more hot in recent years has shown us the life and death test faced by small and medium-sized e-commerce after burning money. Chen Wenjun and Xia Dejian (2016) analyzed the problems of low sensitivity, high passenger flow maintenance costs, and malicious competition in the operation of small and medium e-commerce [7]. Chen Chao and Cao Han (2016) believe that my country's SME e-commerce is still in the preliminary stage of development and is restricted by many factors [8]. Zhou Shuai (2017) believes that the biggest problem in the development of my country's small and medium-sized e-commerce is that without its own e-commerce platform, it is impossible to effectively integrate the internal resources of the enterprise. It can be seen that the problems in the development of small and medium e-commerce have become more and more prominent, and have evolved from the initial development problem to the cruel survival problem [9].

Guo Yinghong (2016) pointed out the rapid growth of small and medium e-commerce companies in product promotion, customer maintenance, online advertising and promotion costs, and analyzed the path of the leading strategy of marketing costs for small and medium ecommerce companies and gave relevant suggestions [10]. Ye Qijing and Zhang Xuefeng (2016) thoroughly explored the five advantages of online celebrity ecommerce and the five disadvantages of small and medium-sized e-commerce companies, and proposed the transformation concept of "integration and replication" [11]. Xiang Weifeng (2016) will compare social ecommerce with self-operated malls and trading platform models and point out that small and medium-sized enterprises need to customize products based on consumer demand and make effective choices of trading platforms to realize business model innovation [12]. Li Yuqing, Zhang Yizhao and Zhang Yanjun (2018) take Jiaxing small and medium e-commerce companies as the research objects, analyze the influence of emerging financing models on the financing capabilities and financing costs of such companies in the context of Internet finance, and then propose corresponding business model innovations Recommendation [13]. Meng Zhiqing and Lu Zhixiang (2018) constructed the business operation model framework of small and medium retail e-commerce enterprises, and pointed out that small and medium retail enterprises should maximize their strengths and avoid weaknesses, 
strengthen their advantages in demand locking and customer positioning, improve product innovation awareness, and combine their own characteristics to provide customers with differentiated products And services, thereby improving the innovation ability and core competitiveness of enterprises [14].

\section{THEORETICAL ANALYSIS}

\subsection{Theoretical Analysis of Internet Celebrities}

In recent years, people's research on business models has gradually diverged into two different levels of meaning: on the one hand, at the practical level, business models only refer to the specific methods and ways that companies engage in their own business activities based on actual conditions; on the other hand, at the theoretical level, The researcher will focus on the meaning and connotation of the business model model itself. The two are essentially different: the former generally refers to the way companies engage in business, while the latter uses a conceptual approach to generalize this way. The theoretical basis used in this article also focuses on the latter, that is, to generalize the basic model of the business model in a conceptual way, so as to find a solution to the problem.

The author believes that the eight elements of the business model are "maximum customer value", "integration", "high efficiency", "system", "profit", "realization form", "core competitiveness", and "overall solution". Among them, integration + high efficiency + system is the foundation of the business model, realization form + core competitiveness + overall solution are the means to achieve the business model, and maximum customer value + continuous profitability is the ultimate goal. In summary, the three core elements of the business model should be summarized as customer value, corporate resources and capabilities, and profitability. Among them, "customer value" refers to the products provided by the company to customers or consumers based on a set price. And services, as well as the added value brought by this transaction: "corporate resources and capabilities" refer to the capabilities that companies must have to achieve customer value and profit models: profit models refer to the process by which companies achieve economic benefits and gain profits. It can be seen that the three core elements of the business model interact and promote each other.

Of course, the definition of the business model and its elements are not static. The true value of the business model should be reflected in its actual application process, especially in small and medium-sized enterprises, and through no matter what kind of strategic planning operation model is adopted, A successful business model has the following characteristics: one is to increase sales profit margins, the other is to increase sales speed and market capacity, thereby increasing the speed of asset turnover, and the third is to achieve a winwin goal for suppliers, customers and enterprises.

After 2015, online celebrity's e-commerce has increasingly entered our lives, and have changed from a single social phenomenon to an economic phenomenon. Restricted by the supply chain, many celebrity shops selling women's clothing have gradually got rid of the model of picking up goods at stalls, taking pictures, and selling at a price increase, and instead use OEM methods to upgrade and optimize their own stores. During this period, Internet celebrity's e-commerce gradually sprouted the consciousness of "brand creation" in the operation process. At the same time, the popularity and traffic gathered from social platforms have turned to the self-operated stores of Internet celebrities, and brought huge profits to these Internet celebrities e-commerce, and the phenomenon of cyber celebrities has become an economic phenomenon.

\subsection{Theoretical Analysis of E-commerce Marketing}

As a brand-new business model, e-commerce is no longer applicable to the traditional marketing framework. The e-commerce environment has fundamentally changed traditional marketing. Its emergence and development have led to changes in marketing strategies and concepts. With the three advancements of marketing theory mentioned earlier, many companies have gradually realized the importance of customer relationship management and have begun to pay attention to the research and optimization of customer relationship management issues in order to narrow the relationship with customers.

$4 \mathrm{R}$ marketing puts forward the specific operation form of how to establish relationships, have customers for a long time, and ensure long-term benefits. This is a big turning point in the history of relationship marketing. The premise of $4 \mathrm{R}$ marketing is that companies need to keep close contact with customers, increase their response speed to the market in their interactions with customers, and finally integrate the returns provided by customers with the company's own products to achieve a win-win situation. Therefore, we believe that in the fiercely competitive e-commerce industry, $4 \mathrm{R}$ marketing theory has universal applicability, especially in the process of small and medium-sized e-commerce the constant source of customer value also conforms to the development trend of social e-commerce with social interaction as the main mode.

The essence of Internet celebrity e-commerce begins with social networking and ends with marketing. Under the economic background of e-commerce, the focus of corporate marketing has changed from managing marketing mix to interactive relationship marketing with customers. It is not difficult to see that the development 
trend of modern marketing is shifting from transactional marketing to relationship marketing, not only to win customers, but also to emphasize long-term customer ownership; from focusing on short-term benefits to focusing on long-term benefits; from one-way sales to establishing two-way partnerships ; From focusing on product performance to focusing on the benefits of products or services to customers; from not focusing on customer service to highly committed services. Especially in the women's clothing industry, if companies can attach importance to communication management with customers, provide a platform for customers to participate in the operation of the company, use social platforms to achieve information sharing, and achieve "the company clearly grasps customer preferences and customer transparency Understand the two-way communication of the operation of the enterprise, and then create products and services through the standards of personalized design and brand operation, establish a long-term development mechanism and a good shopping atmosphere, so as to compete for small and medium e-commerce in the market This is not only the enlightenment brought by the theory of customer relationship marketing, but also the key point in this article to study the e-commerce of Internet celebrities and solve the plight of small and medium-sized ecommerce operations.

\section{RESEARCH ON THE DEVELOPMENT STATUS OF SMALL AND MEDIUM- SIZED E-COMMERCE IN WOMEN'S CLOTHING IN MY COUNTRY}

\subsection{Industry History and Success Factors}

At present, e-commerce Internet celebrities selling small and medium women's clothing mainly rely on social platforms as traffic portals to attract fans. Zhang Dayi, Onlyanna, Lin Shanshan, Teng Yujia, Zuo Jiaojiao, and Daxi are among the more successful Internet celebrities. From 2016 to 2018, three consecutive years of Taobao double eleven women's clothing transaction volume, more than $70 \%$ of the celebrity stores ranked in the top ten.

First of all, in terms of corporate resources and capabilities, Taobao, Weibo, and live broadcast platforms from the external environment have greatly boosted the rise of the Internet celebrity economy. People can easily access these platforms, which has greatly changed the shopping behavior of mobile users. In addition, the product itself is no longer the only starting point for the user's purchase behavior. It is more that the idol effect brought by the Internet celebrities themselves leads to consumer consumption. Platform e-commerce is becoming more and more mature, and its competition is also fierce. The frenzied way of competition has ended, and the era of refined and personalized competition is coming. Therefore, at this time, data analysis must be carried out. Whether you are a big seller or a small seller, data analysis is one of the items that every e-commerce practitioner must learn. For example, Taobao's big data analysis provides a powerful direction for many sellers' sales strategies. With the support of Taobao's big data, Internet celebrities can understand fan preferences in real time in the sales background. For example, which picture brings in more traffic, which product gets more attention and collection, and which single product gets higher sales, all of which allow Internet celebrities to position themselves more accurately on social media and facilitate optimized promotion. Invest.

Secondly, branded strategic operations and strong supply chain management are internal guarantees for the success of e-commerce operations of Internet celebrities. Whether it is ordinary e-commerce or Internet celebrity e-commerce, it must eventually return to the essence of commerce-focusing on products and improving supply chain efficiency. Successful online celebrity e-commerce is to use the life cycle of internet celebrities to inject brand value into their products, and to transform internet celebrity fans into brand fans. The increase in brand value directly determines how far the Internet celebrities can go. This is the most fundamental way of making money in e-commerce. The core of branding operation is the efficiency of supply chain management, especially in women's clothing companies with less publicity and more styles. In the past, there was ZARA, which claims that the product can be as fast as 7 days from design to shelf. The internet celebrity e-commerce company Ruhan with the flexible supply chain model of "turning orders". And Feng Min, CEO of Ruhan, said more than once that the responsibility of contemporary e-commerce is not simply selling goods, but through the trinity link of "social platform interaction + e-commerce big data + ERP system" to achieve vertical integration and create a real Flexible production in the sense. In comparison, some Internet celebrities with inadequate supply chains and weak management capabilities will eventually be short-lived in e-commerce, and will soon be submerged in cruel market competition.

Finally, the use of precision marketing to maximize customer value is the fundamental reason for the success of Internet celebrities in e-commerce. First of all, most of the commodities sold by e-commerce Internet celebrities are low-end consumption, such as women's clothing for summer clothing of about 100-yuan, spring and autumn clothing of about 300 yuan, and winter clothing of about 600-800. This price is completely for students, young white-collar workers, and ordinary workers. Acceptable, this has also created an extraordinary fan base for Internet celebrities. Secondly, most Internet celebrities focus on digging into users in a certain field. When promoting and disseminating information, the arrival rate and acceptance rate of information is relatively high, and 
the interaction with fans is strong, so that we can receive feedback from fans in time, and can quickly respond to design the product into the hearts of fans What I think is in line with the principles of precision marketing. Finally, the premise that fans are customers brings innate advantages to e-commerce internet celebrities, such as high customer loyalty, high stickiness, and strong repurchase rate. At the same time, the taste and vision of internet celebrities themselves, the wearing of clothes and the sensitivity to fashion are both inherent strength and deeply affect the consumer taste of fans. And through the above analysis of the e-commerce business model of Internet celebrities, we can also find that the market mechanism has changed. It turned out that I put one, two, three, and beg you to buy. Now it has become the buyer's choice. , I beg me to sell, or even directly adopt hunger marketing, first collect the deposit and then produce, it can almost reduce the operational risk to zero.

\subsection{SWOT Analysis of Business Model}

\subsubsection{Development advantages}

(1) The shop is small in scale and the business model is more flexible

Generally speaking, it is easier for small and medium-sized enterprises to enter the market, because the flexibility of their business model is conducive to rapid adaptation to the current market environment, and rapid adjustment of product structure according to market changes, changing the direction of production, with strong vitality.

\section{(2) Lower cost of obtaining information resources}

Thanks to the openness and global characteristics of e-commerce itself, SMEs can pay a lower cost to obtain the same information resources as large enterprises when entering the e-commerce market. In the Internet economy environment, if SMEs can play Taking advantage of this advantage, using a variety of open social platforms and rich information resources to build their own shopping community, then in the new round of market competition can be more vigorous.

(3) Suitable for introducing flexible supply chain mechanism

Compared with large-scale traditional e-commerce, small and medium-sized e-commerce purchases are smaller in a single purchase, and come from different suppliers, especially some self-operated stores. They have a lot of autonomy in the selection of sources of goods and supply chains. So in its transformation, it can fully utilize this advantage and directly introduce a flexible supply chain with quick response, small quantity and large quantity, so as to realize the customized demand for customers.

\subsubsection{Development disadvantages}

(1) The lack of capital, technology, and talents has led to weak business capabilities, and the instability of the supply chain and unscientific strategic policies restrict the upgrade and transformation of enterprises.

(2) The vicious circle of low perception and lowprice competition in online shopping for women's clothing has severely affected customers' shopping experience and reduced customer loyalty.

(3) The marketing model is too single. Most small and medium-sized e-commerce companies that rely on the platform for survival often only adopt a simple promotion model that focuses on burning money to buy traffic. In the formulation of marketing strategies, they are prone to fall into the imbalance of marketing costs and profits, price and promotion are contradictory, and pricing is not. Reasonable, false promotions, lack of experience and awareness of consumer purchase behavior, insufficient marketing accuracy, lack of aftersales, service, and credibility. The reason is that small and medium e-commerce excessively pursue traffic when formulating marketing strategies and sales, ignoring the long-term mechanism and precision of marketing management, the result is twice the result.

\subsubsection{Development opportunities}

(1) The assistance of "Internet +" technology and its concept

The core of "Internet + " is to further deepen the integration and connection between the network and traditional industries through mobile Internet, cloud computing, big data, Internet of Things and other technologies. For the women's clothing industry, technologies and concepts such as big data, sharing platforms, and mobile payments have brought new opportunities for traditional small and medium-sized ecommerce in precision manufacturing, fine management, supply chain optimization, deepening of customer relationship management, and after-sales response.

(2) Transformation opportunities brought by mobile social

The development of China's e-commerce industry is converging to the "land rent" model in the traditional economy. Platform giants control the flow, and small and medium-sized enterprises enter and develop by purchasing "lots" on the platform. The innovation of Internet technology, the change of user behavior habits, and the decentralization of traffic portals have brought another model-social e-commerce into our lives. In fact, as early as 2014 Nielsen published

"Mobile social user needs and behavior survey report" shows that $90 \%$ of users use mobile social apps every day. In the era of mobile Internet, traffic is 
concentrated on social apps. Many businesses see the opportunities behind it, and traffic entrances are changing.

\subsubsection{Potential threats}

\section{(1) Limitations of platform mode}

The emergence and development of online shopping platforms is a double-edged sword for small and medium e-commerce. The rules of the platform model also directly determine the living environment of these small and medium-sized sellers. In the early days of ecommerce development, platforms such as Taobao and T-mall attracted a large number of small and mediumsized enterprises because of low thresholds. Tens of millions of sellers and the platform have experienced rapid development together. The stage. However, the market is not expanding unlimitedly. The crushing of ecommerce by large brands and Internet celebrities has led to increased platform promotion costs and changes in search ranking rules have caused small and medium ecommerce to focus most of their efforts on the adaptation of platform rules and the search for keywords. Optimization rather than more important supply chain optimization and product service and quality. If things go on like this, many small and medium-sized e-commerce companies will easily fall into the vicious circle of fraudulent transactions. This abnormal operational mentality is not only detrimental to its own development, but also disrupts the healthy development of the market economy.

\section{(2) The cost of traffic continues to rise}

When platform e-commerce develops to a certain stage, traffic will inevitably be reduced. What's more, there are many other e-commerce models to grab traffic. For example, $\mathrm{O} 2 \mathrm{O}$ e-commerce has emerged in the past two years to provide customers with a more convenient and better shopping experience. Competitors such as commerce, JD.com supported by an efficient logistics system, self-operated supply chain, and strong online and offline integration of Suning, etc., for small and mediumsized sellers who rely too much on platform production, they will inevitably face high customer acquisition costs.

\section{CONCLUSION}

\subsection{Research Results of This Article}

Through research, it can be seen that there are challenges and opportunities for the development of small and medium-sized e-commerce under the network background. The ever-expanding popularity of the Internet has been synchronized with the emergence and development of e-commerce, thus promoting the birth of the Internet celebrity economy. Internet celebrities collect popularity on the platform, accumulate fans, and introduce their own stores after they have a certain foundation. Fans have brought huge profits to Internet celebrities in e-commerce, and the phenomenon of Internet celebrities has turned into an economic phenomenon, especially during the epidemic. As a new type of business model, e-commerce applies the $4 \mathrm{R}$ theory to bring continuous customer value for enterprises, and conforms to the development trend of ecommerce based on social interaction. Based on this premise, small and medium-sized enterprises can also adapt to marketing methods such as the Internet celebrity economy.

\subsection{Suggestions}

Small and medium-sized e-commerce should take advantage of the network. It is easy for SMEs to enter and exit the market, with their small scale and flexible business model, so they can quickly adapt to the market environment, and due to the openness and global nature of e-commerce, small and medium-sized e-commerce can easily contact and use existing resources. Such enterprises should introduce a flexible supply chain mechanism, because small and medium-sized ecommerce business scales and purchases are relatively small. Compared with large traditional e-commerce, small and medium-sized e-commerce purchases at a time are small, especially for some self-operated Stores can freely choose suppliers. Therefore, with this advantage, small and medium-sized e-commerce can directly introduce flexible supply chains, quickly and economically deal with environmental or environmental uncertainties in production and operation activities, thereby realizing customization for customers' demand. Companies should also attach importance to communication with customers, allow customers to participate in the operation of the company, and use social platforms to share information. First achieve twoway communication, and then create products and services through personalized design and brand operation standards, achieve precision marketing, establish a long-term development mechanism and a good shopping atmosphere to maintain small and medium-sized e-commerce in the market.

\section{REFERENCES}

[1] Yang Chunyao. Analysis of Net Red and Net Red Economy [J] Modern Business, 2017:(6):3

[2] Wang Jing, Cui Can, Gao Sijia, Qian Xuelun. The leap from "net celebrity" to "net celebrity economy"-Taking Papi sauce as an example. Modern Economic Information, 2016 (8): 370-371

[3] Zhou Ping. Internet celebrities and Internet celebrity economy in the self-media era $[\mathrm{J}]$, Chinese and foreign entrepreneurs, 2017 (27): 46 
[4] Ding Zhongxian, Xu Wanting. The emergence and development of Internet celebrity e-commerce [J] China Economic and Trade, 2016 (23): 64

[5] Liu Xiaoqian, Yu Yangfei, Han Mei. Analysis of the operation mode of online celebrity e-commerce- Taking "My Happiness Wardrobe" as an example of online celebrity Zhang Dayi[J]. Art Theory, 2017 (5): 44

[6] Du Lishuang. Analysis of the status quo and development countermeasures of Internet celebrity e-commerce in the Chinese market [J], 2017 (15): 32

[7] Chen Wenjun, Xia Dejian. Taking advantage of mobile internet to seek new opportunities for the development of small and medium e-commerce [J] China Collective Economy, 2015 (3): 25-26

[8] Chen Chao, Cao Han. Analysis of the status quo of ecommerce development of small and medium-sized enterprises [J] Market Modernization, 2016 (4): 21

[9] Zhou Shuai. Talking about the status quo and development trend of e-commerce [J]. Computer Knowledge and Technology, 2017 (3): 20-21

[10] Guo Yinghong. Path Analysis of Leading Strategy of Marketing Cost of E-commerce Enterprises [J]. Friends of Accounting, 2016 (12): 23-25

[11] Ye Qijing. Zhang Xuefeng. The development of online celebrity e-commerce in traditional mediumsized enterprises [J]. Fujian Computer, 2017 (6): 1517

[12] Xiang Weifeng. Comparison of business models between SNS social e-commerce and traditional ecommerce [J]. Business Economics, 2016 (5): 142144

[13] Li Yuqing, Zhang Yizhao, Zhang Yanjun. Research on Business Model Innovation of Small and Medium-sized E-commerce Enterprises in Jiaxing City under Internet Finance_—_Taking Maibaobao as an example Ding E-commerce[J], 2017(9): 46

[14] Meng Zhiqing and Lv Zhixiang Study on the Framework of E-commerce Business Operation Model of Small and Medium Retail Enterprises [J]. Journal of Zhejiang University of Technology, 2018 (5): 53 